\title{
Coral planulae as dispersion vehicles: biological properties of larvae released early and late in the season
}

\author{
K. O. Amar ${ }^{1,2}$, N. E. Chadwick ${ }^{2,3}$, B. Rinkevich ${ }^{1, *}$ \\ ${ }^{1}$ Israel Oceanographic and Limnological Research, Tel-Shikmona, PO Box 8030, Haifa 31080, Israel \\ ${ }^{2}$ The Mina and Everard Goodman Faculty of Life Sciences, Bar-Ilan University, Ramat Gan, Israel \\ ${ }^{3}$ Department of Biological Sciences, 101 Rouse Life Sciences Building, Auburn University, Auburn, Alabama 36849, USA
}

\begin{abstract}
Over the last century, considerable research has been dedicated to investigating life history traits of coral planulae. However, despite the universality of coral propagules and their deduced ecological properties, there is no clear understanding of some basic biological issues such as ecological and evolutionary forces that determine sexual reproduction and larval behavior in hermatypic corals. To further evaluate ecological trajectories in sexual reproduction of the hermatypic coral Stylophora pistillata from Eilat, Red Sea, we collected 22900 planulae from 313 S. pistillata colonies in situ during March to July (2004 to 2006). Variations in reproductive effort were observed between years, but during all reproductive seasons, the larvae tended to settle ex situ in aggregates of kin $(61.71 \%$ to $82.4 \%$; 2005 values). During a 6 mo survey, the spat grew at a rate of 3.4 to 5.4 polyps mo ${ }^{-1}$. Peaks of planula shedding were documented for April to June, suggesting a shift in reproductive seasonality compared to the preceding 2 to 3 decades. Ex situ settlement of collected larvae revealed, for the first time, settlement polymorphism of early versus late larvae throughout the reproductive season; the March settlement rate was the highest $(43.7 \%)$ and June was the lowest $(26.2 \%)$. A reverse trend was documented for settlement rates on the first post-planulation night, with only $2.2 \%$ settlement in March versus $46.2 \%$ in July. Early season larvae of S. pistillata are therefore capable of dispersing farther than late season propagules. These results are diametrically opposed to the 'desperate larva hypothesis,' revealing different ecological traits of early versus late season larvae.
\end{abstract}

KEY WORDS: Reproduction · Aggregation · Settlement $\cdot$ Recruitment $\cdot$ Coral $\cdot$ Eilat - Resale or republication not permitted without written consent of the publisher

\section{INTRODUCTION}

Studies on coral reproductive activities over the past 3 decades have led to increasing understanding of coral sexual reproduction, including issues related to planulae larvae and their settlement behaviors under ex situ and in situ conditions. Wild-caught coral gametes, embryos, and larvae, ex situ settled planulae, and farmed coral spat are often used in biological assays that address a myriad of scientific issues, such as habitat preference by coral larvae (Baird et al. 2003), characteristics of planula behavior (Atoda 1947a,b, 1951a,b, Harrigan 1972), patterns of larval dispersal (Nozawa \& Harrison 2002, Miller \& Mundy
2003, Nishikawa et al. 2003, Harrison 2006), coral immunity (Hidaka 1985, Frank et al. 1997, Hidaka et al. 1997), reef conservation and rehabilitation (Petersen \& Tollrian 2001), use of corals in the ornamental trade (Petersen et al. 2005, 2006), and substrate type preference (Harrigan 1972, Petersen et al. 2005). Evaluating ex situ settlement patterns could increase our understanding of settlement behavior and coral recruitment in situ due to the ability to isolate the influence of single variables (Bassim \& Sammarco 2003).

Competency windows for settlement during the ontogeny of reared planula larvae under controlled ex situ conditions could offer a good estimation for the 
dispersal potential of planula larvae in the sea. One such example (Nishikawa et al. 2003) compared the ex situ settlement rates and population genetic structure of 2 coral species: the broadcaster Acropora tenuis, and the brooder Stylophora pistillata. This study revealed that the expected longer competency periods of $A$. tenuis larvae correlated tightly with higher rates of gene flow. Both results suggested that $A$. tenuis planulae disperse over larger distances than do $S$. pistillata larvae. Correlation between ex situ settlement results and genetic analysis of the brooder species Seriatopora hystrix have also been documented; Atoda (1951a) observed a short competency period with most planulae settling within $24 \mathrm{~h}$ after release. Much later, studies that employed 2 genetic tools-allozyme (Ayre \& Dufty 1994)

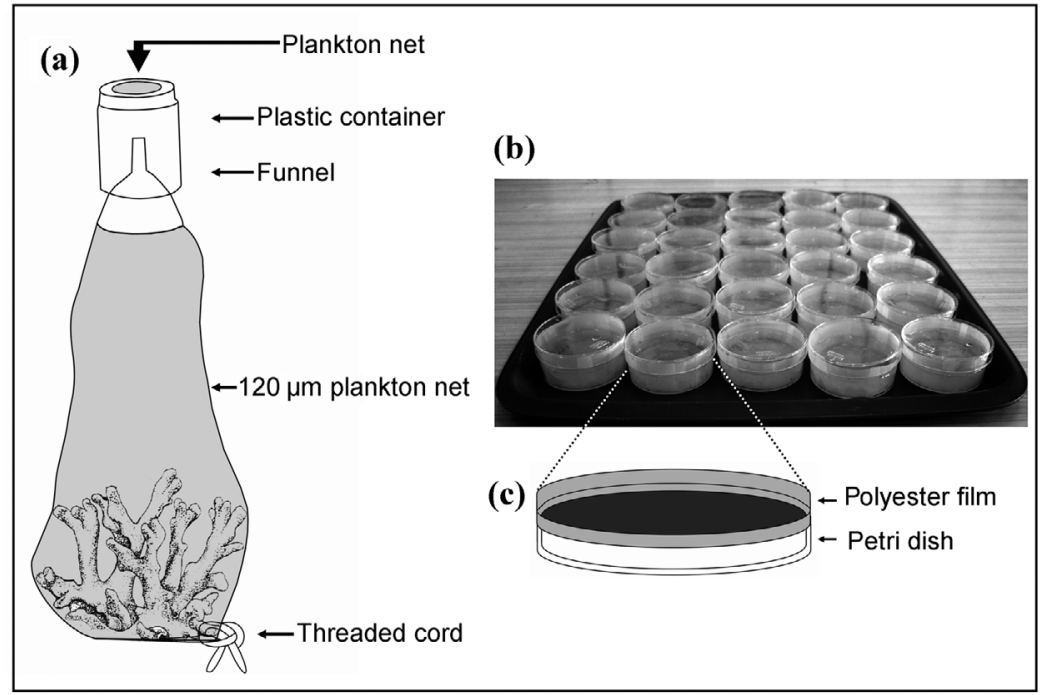

Fig. 1. (a) Planula trap used for Stylophora pistillata planulae collections. (b) Set of Petri dishes containing $S$. pistillata planulae. (c) Schematic illustration of a Petri dish

and microsatellite markers (Maier et al.

2005) - revealed effects of isolation by distance on a small geographic scale, indicating limited dispersal of larvae.

We evaluated ex situ settlement patterns and rearing of planula larvae collected in situ from gravid Stylophora pistillata colonies during 3 consecutive reproductive seasons. We used Petri dishes lined with polyester film for the settlement assays and evaluated settlement rates, settlement patterns, growth rates, and survivorship of spat. We found differences in biological properties of larvae released early and late in the season, differences between years, and shifts in reproductive seasonality compared to the previous 2 to 3 decades.

\section{MATERIALS AND METHODS}

Planula collection and transportation. Stylophora pistillata is a hermaphroditic coral species with a lengthy reproductive season (January to July, Rinkevich \& Loya 1987). Planula larvae were collected in situ during 3 successive reproductive seasons (2004 to 2006). Collection days were arbitrary with respect to the lunar cycle, and included 3 to $8 \mathrm{~d}$ of collection per month during the reproductive season of March to July of each year. Field collections were performed at depths of 3 to $6 \mathrm{~m}$ on coral reefs adjacent to the Interuniversity Institute for Marine Sciences (IUI, Eilat, Red Sea) using nylon mesh traps placed over gravid $S$. pistillata colonies (15 to $20 \mathrm{~cm}$ in diameter; Fig. 1a) before sunset, and removed the following morning. Each trap was made of a plastic container, connected to a $120 \mu \mathrm{m}$ plankton net through a plastic funnel (Fig. 1a; see also photograph in Zakai et al. 2006). A $7 \mathrm{~cm}$ diameter hole in the container's lid was lined with nylon mesh to allow free water exchange in the field. Traps that covered colonies in the field were secured to the bottom by threaded cords (Fig. 1a). Released larvae were caught in the plastic containers. In the laboratory, collected planulae were flushed using a gentle current of seawater flowing toward the nylon mesh lining the lid of the plastic container; the lid was then immersed in a collecting dish, and planulae were rinsed off using a minimal quantity (ca. $100 \mathrm{ml}$ ) of filtered $(25 \mu \mathrm{m})$ seawater. Planulae were reared either in the laboratory at Israel Oceanographic and Limnological Research (IOLR) in Haifa, Israel, or in outdoor aquaria at the IUI facility at Eilat. The larvae were transported to the laboratory in Haifa (6 h travel time) in groups of 30 planulae (in a plastic cooler, under controlled water temperature) within $2 \mathrm{~d}$ after collection, each group in a $50 \mathrm{ml}$ plastic tube containing filtered seawater ( $25 \mu \mathrm{m}$; Frank et al. 1997, Amar \& Rinkevich 2007).

Planula settlement and spat rearing. Upon arrival in Haifa, the content of each plastic tube was transferred to a Petri dish. Swimming planulae were counted and transferred to settlement dishes. The small number of planulae that metamorphosed on the tubes' plastic walls during transportation were counted. In preliminary experiments, the remaining larvae were transferred onto settlement dishes lined with 3 types of substrate: Saran Wrap plastic film, inkjet printer transparency film, and polyester film with double-sided matte (Euroridel International). The plastic film 
yielded very low settlement rates, probably due to its overly smooth surfaces. The printer transparency film, with an originally rough surface, became smooth within a few days in the seawater, causing increased mortality of planulae in the Petri dishes. In contrast, the polyester film not only yielded the best settlement rates but was also easily marked with pencil for efficient follow-up observations. Thereafter, studies were performed on $60 \mathrm{~mm}$ Petri dishes lined with pieces of polyester film (Fig. 1b) that were preconditioned in flow-through aquaria for $1 \mathrm{wk}$. Each Petri dish with polyester film-covered walls (Fig. 1b,c) held up to $45 \mathrm{ml}$ of seawater. Upon arrival at the laboratory, the free-floating and metamorphosed planulae were counted and distributed in groups of 15 to 110 planulae per Petri dish. All Petri dishes and settlement experiments were kept in a temperature-controlled room $\left(25^{\circ} \mathrm{C}\right)$. Each planula that settled was numbered by pencil on the polyester film, and then the surrounding film was cut away, leaving the spat on a small disc of film, which was attached to a $5.0 \times 7.5 \mathrm{~cm}$ glass slide using cyanoacrylate glue (Super Glue 3, Loctite). Since the glue did not come into direct contact with the coral tissues and all transfers were performed under running seawater, there seemed to be no harm done to the coral tissues.

Larvae that metamorphosed on the water surface in the Petri dishes (oral side down) were picked up gingerly on the tip of a fine paintbrush, placed (15 min) in a humidified chamber on small pieces of polyester film that had been pre-glued to glass slides, incubated in standing water aquaria overnight, and then transferred to flowing seawater aquaria. In Haifa, the glass slides with settled primary polyps were transferred to flow-through aquaria (Mediterranean water, temperature controlled, 23 to $25^{\circ} \mathrm{C}$ ) under a $12: 12 \mathrm{~h}$ light:dark regime (approximately $300 \mu \mathrm{mol}$ photons $\mathrm{m}^{-2} \mathrm{~s}^{-1}$ ). Since seawater in the Haifa system was filtered, the coral spat were fed every other day with fresh Artemia. In Eilat, rearing took place in outdoor flow-through aquaria shaded by nets that reduce solar radiation by $80 \%$ (approximately $330 \mu \mathrm{mol}$ photons $\mathrm{m}^{-2} \mathrm{~s}^{-1}$, during the experiment months). Coral spat reared at Eilat were not fed, but had access to natural plankton food that entered in the flow-through seawater system.

Spat were observed under a Nikon SMZ800 stereomicroscope once a week for up to 6 mo. Debris and fouling organisms were removed from the slides and from coral using small razor blades and fine paintbrushes. Growth was measured in terms of the number of polyps per coral per unit time. During 2004 and 2005, experiments were carried out in Haifa, and in 2006, the experiment was done in Eilat. Young colonies were photographed using a Color View 2 Soft Imagin System camera equipped with a millimeter grid for scale.
Statistical analysis. Data were processed with SPSS software version 10 for Windows and Windows Excel. Results were analyzed using nonparametric tests. Spearman's test was used for correlations between number of planulae per dish and settlement rates and for aggregate analyses. For variance analyses we used Kruskal-Wallis (number of planulae released within each month and growth rates) and Mann-Whitney tests for pairwise comparisons of planulae released between months and for literature comparisons of brooders versus broadcasters, and chi-squared tests for independence between settlement rates. Results are presented as mean \pm SD except where indicated.

\section{RESULTS}

In total, 22900 planulae were collected from 313 Stylophora pistillata colonies in March to July during 3 consecutive reproductive seasons (2004 to 2006; except March 2006, Fig. 2), and 19 planulae were collected from 10 other colonies in August 2004 (data not presented). In this last collection, 9 of the colonies released 0 to 1 planula each, and a single colony released 15 planulae. The number of planulae released per colony varied significantly between years in March and April (Kruskal-Wallis test, p < 0.05) but not between years in May, June, and July (Kruskal-Wallis test, $\mathrm{p}>0.05)$. The maximum number of planulae released by a single colony in 1 night during each reproductive season was 500 in May 2004, 1636 in March 2005, and 353 in April 2006. April to June represented the peak of the reproductive season. The number of planulae per colony in March and July was not significantly different $(56.9 \pm 20.8$ vs. $18.3 \pm 2.9$, mean $\pm S E$, respectively, Mann-Whitney test, $p>0.05$ ),

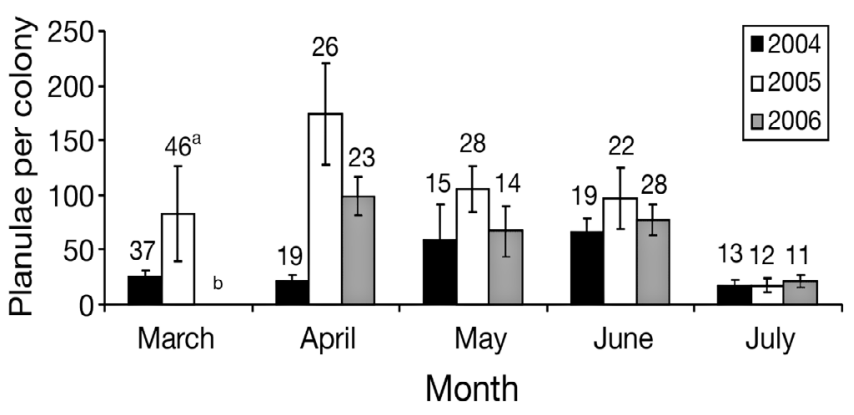

Fig. 2. Stylophora pistillata. Reproductive effort during March to July 2004 to 2006 (mean \pm SE number of planulae released per colony). The number of colonies sampled is marked above each column; ${ }^{a}$ when excluding an extreme case of 1636 planulae released by a single colony (the maximal number of larvae per colony, per night, during the whole $3 \mathrm{yr}$ period), the average number of planulae per colony for this sampling month was $48.2 \pm 14.5 ;{ }^{b}$ no collection was conducted 
but was significantly lower than the number of planulae collected in April, May, and June (105.7 \pm 18.9, $83.9 \pm 14.2$, and $80.3 \pm 10.9$, mean $\pm \mathrm{SE}$, respectively, pairwise comparisons using Mann-Whitney test, p < 0.001). Peak larvae release was in April 2005 (173.5 \pm 46.4 planulae per colony per night, mean \pm SE, Fig. 2). In contrast, $S$. pistillata colonies released only 0 to 58 planulae per colony during July each year (Fig. 2). During the peak of the reproductive season (April to June), only $2 \%$ of the observed colonies failed to release any planulae, compared to $12 \%$ in July and 13.9\% in March (Fig. 3). During April to June, 49.2\% of $S$. pistillata colonies released more than 51 planulae per colony per night, while in March and July only 20.5 and $8.3 \%$, respectively, released this number of planulae per night (Fig. 3).

The settlement pattern of the 11537 planulae collected in 2005 was monitored closely for 3 wk (Figs. 4 \& 5). About $90 \%$ of the planulae survived the first 3 wk (range: $87.2 \%$ in March 2005 to $94.3 \%$ in April 2005), and actively swimming planulae were observed up to 3 mo after planulation. Settlement rates during the first night (15.6\% of the total released planulae settled within the plankton traps; Fig. 4) and the second day after planulation (13.2\% settlement during transportation to Haifa; Fig. 4) revealed a tendency for rapid metamorphosis of freshly released Stylophora

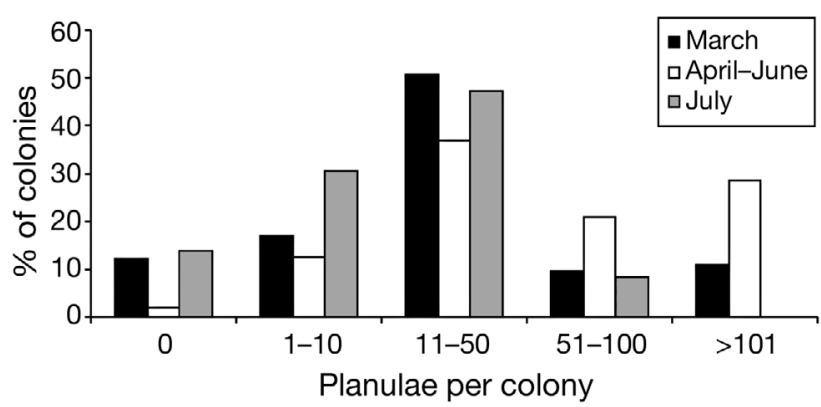

Fig. 3. Stylophora pistillata. Percentages of planula-releasing colonies during each reproductive season

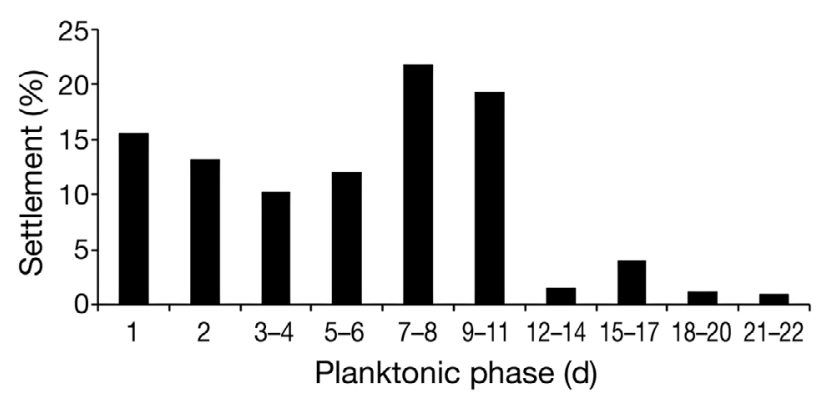

Fig. 4. Stylophora pistillata. Distributions of planula settlement during the first 3 wk post planulation (data from the 2005 collection season)

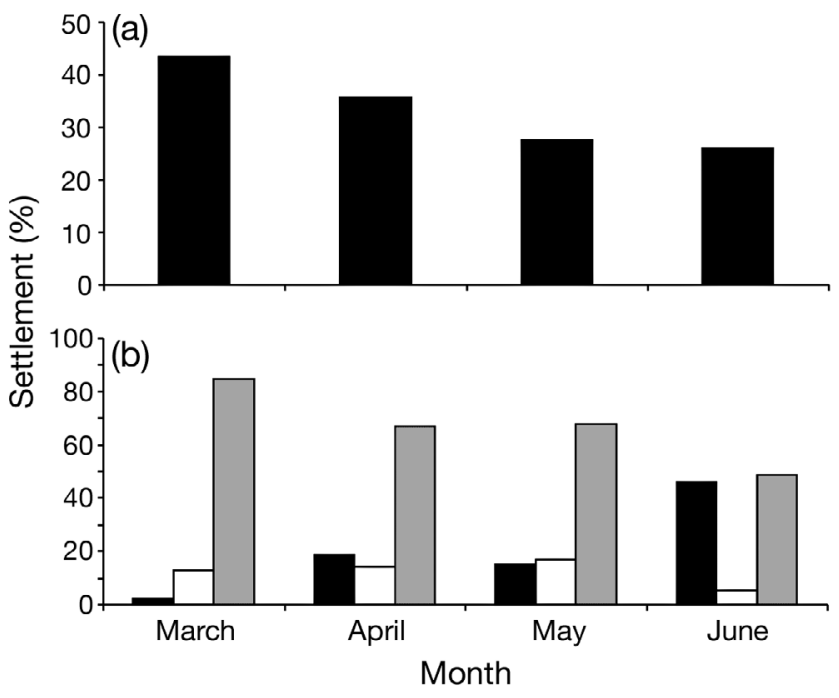

Fig. 5. Stylophora pistillata. Detailed settlement patterns for planulae. (a) Settled larvae out of the total released, per individual coral, per month. (b) Percentages of larvae that settled on the first night (black bars), during transportation (white bars), and in Petri dishes (grey bars), out of total settled planulae (data from the 2005 collection season)

pistillata planulae. More than $90 \%$ of total settlement (percent of planulae that settled) occurred during the first $11 \mathrm{~d}$ post planulation (Fig. 4).

Settlement rates differed significantly among the reproductive months (Fig. 5a,b, chi-squared, p < $0.001)$. March settlement was the highest $(43.7 \%$ of total larvae released that month), and settlement rates declined gradually toward June (26.2\%; Fig. 5a). A reverse trend was documented for first night postplanulation settlement: the highest value was obtained in June, whereas the lowest was in March (2.2 vs. $46.2 \%$, respectively, chi-squared, p $<0.001$, Fig. 5b).

Nearly $70 \%$ of the metamorphosed planulae settled on the polyester film substrate, and the rest on the water surface tension. Spat that developed from these 2 groups differed significantly in rates of detachment and survival. We closely observed the mode of settlement of 300 planulae. Within the first week, about $28 \%$ of the planulae that metamorphosed on the water surface and transferred to polyester film detached (probably due to the less efficient attachment methodology) and $5 \%$ died, compared to only $4 \%$ detachment and $<1 \%$ mortality of the planulae that settled directly on polyester film (chi-squared, p < 0.001). After 1 mo, 43 and $11 \%$ of the planulae that had initially settled on the water surface detached and died, respectively, compared to 11 and $8 \%$ detachment and mortality, respectively, in the direct-settling planulae (chisquared, $\mathrm{p}<0.001)$.

In 2005, we populated 72 Petri dishes with 15 to 110 kin planulae each (the total number of planulae in 
this experiment was 4905). The settlement rate was not influenced by the initial number of planulae per dish (30.4 to 37.4\%; Spearman's correlation, p > 0.05, Fig. 6). Interestingly, more than $70 \%$ of the planulae settled in aggregations of at least 2 spat, at $<1 \mathrm{~mm}$ from each other. At low densities of 15 to 75 planulae per dish, the percentage of planulae that aggregated did not correlate with density (61.71 to $69.76 \%$ of total settled larvae; Spearman's correlation, $r=0.15, \mathrm{p}>0.05$, Fig. 6), but at higher planula concentrations, it did (79.9 to $82.4 \%$; Spearman's correlation, $\mathrm{r}=0.41$, $\mathrm{p}<$ 0.001, Fig. 6). Some planulae settled in large aggregates of 15 to 20 coral spat.

During the 6 mo survey, the spat grew at 3.4 to 5.4 polyps $\mathrm{mo}^{-1}$ (Fig. 7). The number of polyps per colony did not differ significantly between the 3 cohorts (2004

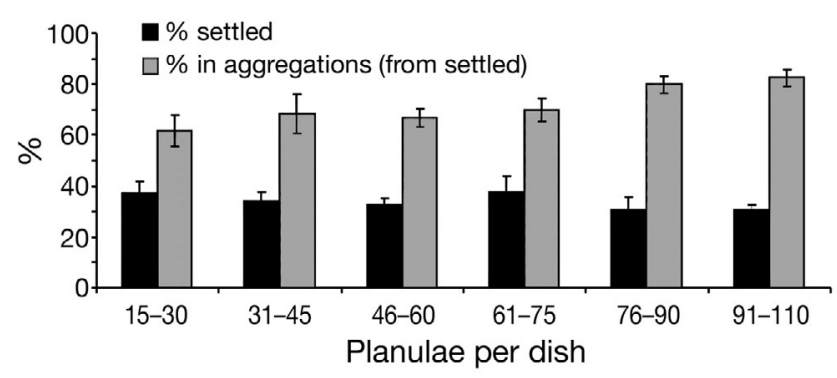

Fig. 6. Stylophora pistillata. Effect of planula density on settlement patterns
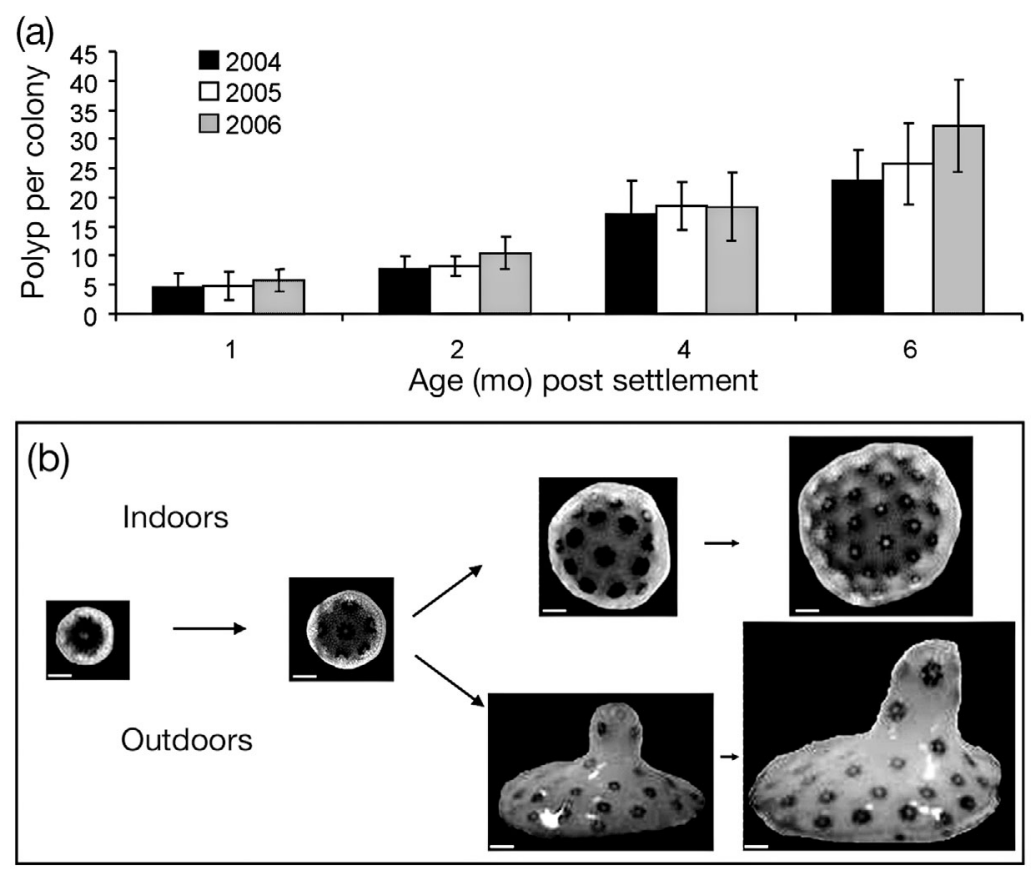

Fig. 7. Stylophora pistillata. (a) Growth during early colony ontogeny (2004 to 2006, $\mathrm{n}=17,20$ and 32 colonies, respectively). (b) Typical colony structures at Haifa and Eilat facilities. Scale bars $=1 \mathrm{~mm}$ to 2006) at the ages of 1 and 4 mo (Kruskal-Wallis test; df $=2$, chi-squared $=2.68$ and 1.52 , respectively, $\mathrm{p}>$ 0.05). However, 2 and 6 mo old colonies grew significantly more polyps in 2006 (Kruskal-Wallis test; df $=2$, chi-squared values are 10.04 [p < 0.05] and 18.20 [p < $0.001]$, respectively). In addition, the average number of polyps per colony of young colonies reared at Eilat and Haifa did not differ, but at the age of $4 \mathrm{mo}, 15 \%$ of the colonies kept at Eilat initiated 3-dimensional (3D) growth, whereas all colonies kept at Haifa remained flat. At the age of $6 \mathrm{mo}, 60 \%$ of the colonies at Eilat neared 3D morphology compared to only a few at Haifa (Fig. 7).

\section{DISCUSSION}

We examined patterns of in situ planulation, ex situ larval settlement, and spat development during 3 consecutive reproductive seasons (2004 to 2006) in the Red Sea branching coral Stylophora pistillata. Our results revealed annual variation in reproductive effort, similar to previous results from the same study location (Rinkevich \& Loya 1987, Zakai et al. 2006). Reproductive effort (as measured by number of planula larvae released per coral colony) during 2005 was by far higher than during both the preceding and the following reproductive seasons. There were also differences in spat growth rates between the facilities. In the IUI outdoor facility at Eilat, the young coral grew faster compared to the indoor facility at Haifa. We conclude that these differences possibly reflect better water quality, irradiance conditions, and/or water flow patterns for the IUI corals.

During the entire study period (2004 to 2006), reproductive seasonality in Stylophora pistillata peaked during April to June, and only a few planulae were collected in August 2004, compared to a previous decade-long survey (1974 to 1983; Rinkevich \& Loya 1987) in which reproductive seasonality peaked during March to May with no planulation in August. Similarly, in 4 out of 10 years of the previous survey (1974 to 1983), none of the examined colonies released any planulae in July, whereas during the present survey, planulae were obtained in all 3 July months. Another significant difference between this 3 yr study and the former $10 \mathrm{yr}$ work (Rinkevich \& Loya 1987 ) is the average number of colonies that were reproductive; whereas 2 to 3 decades ago, $100 \%$ of the wild colonies 
released planulae during March, in our study, we observed that less than $88 \%$ of colonies released planulae. Planulae were always obtained during April to June in all 3 surveys (1974 to 1983 survey, 1998 and 2003 survey, and 2004 to 2006 survey). The reef in Eilat has undergone many changes during the last 4 decades (Rinkevich 2005a), some of which may also influence coral reproductive activities. One possible cause for the research outcomes listed above is the steady increase in Eilat's seawater temperature (posi-

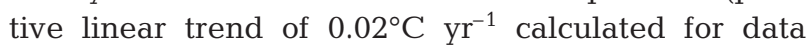
obtained during 1975 to 2003; Gertman \& Brenner 2004). These results therefore indicate a probable shift in the sexual reproductive seasonality of $S$. pistillata during the last 3 decades, potentially connected to global changes.

Larvae of Stylophora pistillata represent a mode of rapid settlement and relatively short competency period (Atoda 1947b, Nishikawa et al. 2003). We analyzed literature data for larval competency of broadcaster coral species in studies that used ex situ settlement techniques (Wilson \& Harrison 1998, Nozawa \& Harrison 2002, Bassim \& Sammarco 2003, Miller \& Mundy 2003, Nishikawa \& Sakai 2005, Harrison 2006, Nozawa et al. 2006, Petersen et al. 2006), and with brooder species (Atoda 1947a,b, 1951b, Gerrodette 1981, Morse \& Morse 1991, Beauchamp 1993, Harii et al. 2002, Nishikawa \& Sakai 2005, Petersen et al. 2005). Whereas these works were constrained by the differences between the studied species and the methodologies used, the analysis (for broadcast species only after the development of the larvae) revealed a significantly earlier peak of settlement in brooders compared to broadcasters $(2.2 \pm 2.4 \mathrm{~d}, \mathrm{n}=6$, vs. $4.7 \pm 2.9 \mathrm{~d}, \mathrm{n}=10$, respectively, mean $\pm \mathrm{SD}$, Mann-Whitney test, $\mathrm{p}<0.05$ ), whereas the length of the competency period in broadcasters was almost twice as long as that in brooders $(39.4 \pm 27.9 \mathrm{~d}, \mathrm{n}=14$, vs. $23.4 \pm 28.4 \mathrm{~d}, \mathrm{n}=12$, respectively, mean \pm SD, Mann-Whitney test, $\mathrm{p}=0.03$ ). Clearly, rapid settlement and reduced competency periods could limit the dispersal of coral planulae to sites near natal colonies (Miller \& Mundy 2003). These findings suggest increased consanguinity of colonies in a specific area and reduced genetic polymorphism of brooder species, including $S$. pistillata, a tenet that warrants further genetic research.

During the 2005 reproductive season, we recorded a sharp decrease $(40 \%)$ in settlement rate from early (March, $43.7 \%$ of the planulae settled) to late phases in the reproductive season (June, $26.2 \%$ of the planulae settled). In contrast, nearly 20 times more planulae spawned in June (46.2\%) settled within $24 \mathrm{~h}$ upon release compared to planulae spawned in March $(2.2 \%)$. These results seem to suggest, on the one hand, intrinsic polymorphism in competency traits that are exhibited by released planulae during various phases of the reproductive season. Planulae released at the beginning of the reproductive season have longer competency periods than planulae released later in the reproductive season. While shallow water ambient temperatures in Eilat vary between different months (Gertman \& Brenner 2004), the collected larvae were not affected by changes in seawater temperature because, upon collection, they were maintained in the laboratory under a constant temperature regimen. On the other hand, the outcome of enhanced settlement of freshly shed planulae during warmer months (within the plankton traps, hours after their release) suggests that water temperatures affect the settlement rates of Stylophora pistillata planulae.

The above results, similar to recent outcomes for other marine invertebrates (Krug \& Zimmer 2000), contradict the predictions of the 'desperate larva hypothesis' (Knight-Jones 1953, Wilson 1953), and document non-homogeneous larval populations that are disclosed in the Stylophora pistillata system by plastic traits for early versus late season coral larvae. Early season 'vagrant' larvae of $S$. pistillata are capable of dispersing farther than are late season propagules. This dispersal polymorphism phenomenon, enhanced by the effect of seawater temperatures, may shape population genetics of coral species. Larval tendency to settle in aggregates and the documented shift in the reproductive seasonality of $S$. pistillata toward the summer months may furthermore enhance changes in population dynamics and genetics of this species in Eilat.

It is further interesting to note that most planulae in the present study settled in aggregates, irrespective of larval concentrations. No significant differences were recorded in the aggregation rates of planulae (about $67 \%$ ) at densities ranging from 1 planula per 0.6 to $3 \mathrm{ml}$ seawater. Greater planulae densities led to increased spat aggregations (up to $81 \%$ of settled larvae). This phenomenon, termed the 'aggregated colonies' phenomenon, was first observed by Duerden (1902). The 'aggregated colonies' phenomenon is a common mode of spat agglomeration in cnidarians that may result in tissue-to-tissue contacts, rejections, or fusions and natural chimeras. It has been documented in the Hydrozoa (Bavestrello \& Cerrano 1992, Wilson \& Grosberg 2004), Scyphozoa (Purcell et al. 2000), and Anthozoa (Hidaka et al. 1997). The literature lists various potential advantages for chimeric entities, e.g. enhanced survivorship due to increased body size, increased fertilization success, and reduced predation risks (Buss 1982, Rinkevich 2005b). However, research outcomes also attest to the cost of chimerism, e.g. competition between cell lineages (Pancer et al. 1995, Stoner et al. 1999, Rinkevich 2005b). Our studies on 
different size spat-aggregates in Stylophora pistillata (authors' unpubl. data), including rejecting and fused partners, further revealed complex life-history traits of kin $S$. pistillata larvae participating in different allorecognition pathways within various size aggregates. Early season spat-aggregates in S. pistillata are therefore assumed to represent less within-aggregate genetic relatedness than late-season spat aggregates (resulting from longer swimming periods), with smaller aggregate sizes (extensive dispersal), and may reveal different within-aggregate interactions (more rejections, less tissue fusions).

In the present study, we evaluated several issues concerning reproduction, planula settlement, and spat development in Stylophora pistillata. We found that long-term observations of reproductive traits in a representative coral species might help in understanding shifts in coral reproductive activities. In addition, polymorphic settlement behaviors indicate variation in biological traits among planulae released during different periods, which, in turn, may influence dispersal patterns over the reproductive season.

Acknowledgements. We thank N. Klein for encouragement and help at early stages; B. Kuguru, D. Yashonsky, and G. Paz for helping with data collection; E. Reem for statistical analysis; J. Douek and S. Shafir for helpful discussions; and the IUI staff. This study was supported by the INCO-DEV project (REEFRES, no. 510657), by CORALZOO, an EC Collective Research project (no. 012547), the AID-CDR program (no. C23-004), and Auburn University. This research fulfulls part of the requirements for the doctoral degree by K.O.A. at Bar Ilan University.

\section{LITERATURE CITED}

Amar KO, Rinkevich B (2007) A floating mid-water coral nursery as larval dispersion hub: testing an idea. Mar Biol 151:713-718

Atoda K (1947a) The larva and post-larval development of some reef-building corals. I. Pocillopora damicornis cespitosa (Dana). Sci Rep Tohoku Univ 4th Ser 18:25-47

Atoda K (1947b) The larva and post-larval development of the reef-building corals. II. Stylophora pistillata. Sci Rep Tohoku Univ 4th Ser 18:49-61

Atoda K (1951a) The larva and post-larval development of the reef-building corals. V. Seriatopora hystrix Dana. Sci Rep Tohoku Univ 4th Ser 19:33-39

Atoda K (1951b) The larva and post-larval development of the reef-building corals. IV. Galaxea aspera. J Morphol 1: $17-30$

Ayre DJ, Dufty S (1994) Evidence for restricted gene flow in the viviparous coral Seriatopora hystrix on Australia's Great Barrier Reef. Evolution 48:1183-1201

Baird AH, Babcock RC, Mundy CN (2003) Habitat selection by larvae influences the depth distribution of six common coral species. Mar Ecol Prog Ser 252:289-293

Bassim KM, Sammarco PW (2003) Effects of temperature and ammonium on larval development and survivorship in a scleractinian coral (Diploria strigosa). Mar Biol 142: $241-252$
Bavestrello G, Cerrano C (1992) Aggregate colonies in Eudendrium glomeratum Picard 1952 (Cnidaria, Hydrozoa, Anthomedusae). Sci Mar 54:333-335

Beauchamp KA (1993) Gametogenesis, brooding and planulation in laboratory populations of a temperate scleractinian coal Balanophyllia elegans maintained under contrasting photoperiod regimes. Invertebr Reprod Dev 23: 171-182

Buss LW (1982) Somatic cell parasitism and the evolution of somatic tissue compatibility. Proc Natl Acad Sci USA 79: $5337-5341$

Duerden JE (1902) Aggregated colonies in Madreporarian corals. Am Nat 36:461-471

Frank U, Oren U, Loya Y, Rinkevich B (1997) Alloimmune maturation in the coral Stylophora pistillata is achieved through three distinctive stages, 4 months post-metamorphosis. Proc R Soc Lond B 264:99-104

Gerrodette T (1981) Dispersal of the solitary coral Balanophyllia elegans by demersal planular larvae. Ecology 62: 611-619

Gertman I, Brenner S (2004) Analysis of water variability in the Gulf of Eilat. Available at: http://isramar.ocean.org.il/ Report1.pdf

Harii S, Kayanne H, Takigawa H, Hayashibara T, Yamamoto M (2002) Larval survivorship, competency periods and settlement of two brooding corals, Heliopora coerulea and Pocillopora damicornis. Mar Biol 141:39-46

Harrigan JF (1972) The planula larvae of Pocillopora damicornis: lunar periodicity of swarming and substratum selection behaviour. $\mathrm{PhD}$ dissertation, University of Hawaii, Honolulu, HI

Harrison PL (2006) Settlement competency period and dispersal potential of scleractinian reef coral larvae. Proc 10th Int Coral Reef Symp:78-82

Hidaka M (1985) Tissue compatibility between colonies and between newly settled larvae of Pocillopora damicornis. Coral Reefs 4:111-114

Hidaka M, Yurugi K, Sunagawal S, Kinzie RAI (1997) Contact reactions between young colonies of coral Pocillopora damicornis. Coral Reefs 16:13-20

Knight-Jones EW (1953) Laboratory experiments on gregariousness during setting in Balanus balanoides and other barnacles. J Exp Biol 30:584-599

Krug PJ, Zimmer PK (2000) Developmental dimorphism and expression of chemosensory-mediated behavior: habitat selection by a specialist marine behavior. J Exp Biol 203: 1741-1754

Maier E, Tollrian R, Rinkevich B, Nurnberger B (2005) Isolation by distance in the scleractinian coral Seriatopora hystrix from the Red Sea. Mar Biol 147:1109-1120

Miller K, Mundy CN (2003) Rapid settlement in broadcast spawning corals: implications for larval dispersal. Coral Reefs 22:99-106

Morse DE, Morse ANC (1991) Enzymatic characterization of the morphogen recognized by Agaricia humilis (scleractinian coral) larvae. Biol Bull (Woods Hole) 181:104-122

Nishikawa A, Sakai K (2005) Settlement-competency period of planulae and genetic differentiation of the scleractinian coral Acropora digitifera. Zool Sci 22:391-399

Nishikawa A, Katoh M, Sakai K (2003) Larval settlement rates and gene flow of broadcast spawning (Acropora tenuis) and planula-brooding (Stylophora pistillata) corals. Mar Ecol Prog Ser 256:87-97

Nozawa Y, Harrison PL (2002) Larval settlement patterns, dispersal potential, and the effect of temperature on settlement of larvae coral, Platygyra daedalea, from the Great Barrier Reef. Proc 9th Int Coral Reef Symp 1:23-27 
Nozawa Y, Tokeshi M, Nojima S (2006) Reproduction and recruitment of scleractinian corals in a high-latitude coral community, Amakusa, southwestern Japan. Mar Biol 149: $1047-1058$

Pancer Z, Gershon H, Rinkevich B (1995) Coexistence and possible parasitism of somatic and germ cell lines in chimeras of the colonial urochordate Botryllus schlosseri. Biol Bull (Woods Hole) 189:106-112

Petersen D, Tollrian R (2001) Methods to enhance sexual recruitment for restoration of damaged reefs. Bull Mar Sci 69:989-1000

Petersen D, Laterveer M, Schuhmacher H (2005) Spatial and temporal variation in larval settlement of reef-building corals in mariculture. Aquaculture 249:317-327

Petersen D, Laterveer M, Van Bergen D, Hatta M and 7 others (2006) The application of sexual coral recruits for the sustainable management of ex situ populations in public aquariums to promote coral reef conservation - SECORE Project. Aquat Conserv Mar Freshw Ecosyst 16:167-179

Purcell JE, Brown ED, Stokesbury KDE, Haldorson LH, Shirley TC (2000) Aggregations of the jellyfish Aurelia labiata: abundance, distribution, association with age-0 walleye pollock, and behaviors promoting aggregation in Prince William Sound, Alaska, USA. Mar Ecol Prog Ser 195:145-158

Editorial responsibility: Howard Browman (Associate-Editorin-Chief), Storebø, Norway
Rinkevich B (2005a) What do we know about Eilat (Red Sea) reef degradation? A critical examination of the published literature. J Exp Mar Biol Ecol 327:183-200

Rinkevich B (2005b) Natural chimerism in colonial urochordates. J Exp Mar Biol Ecol 332:93-109

Rinkevich B, Loya Y (1987) Variability in the patterns of sexual reproduction of the coral Stylophora pistillata at Eilat, Red Sea: a long-term study. Biol Bull (Woods Hole) 173: 335-344

Stoner DS, Rinkevich B, Weissman IL (1999) Heritable germ and somatic cell lineage competitions in chimeric colonial protochordates. Proc Natl Acad Sci USA 96:9148-9153

Wilson ACC, Grosberg RK (2004) Ontogenetic shifts in fusion-rejection thresholds in a colonial marine hydrozoan, Hydractinia symbiolongicarpus. Behav Ecol Sociobiol 57:40-49

Wilson DP (1953) The settlement of Ophelia bicornis Savigny larvae. J Mar Biol Assoc UK 32:209-233

Wilson JR, Harrison PL (1998) Settlement-competency periods of larvae of three species of scleractinian corals. Mar Biol 131:339-345

Zakai D, Dubinsky Z, Avishai A, Caaras T, Chadwick NE (2006) Lunar periodicity of planula release in the reefbuilding coral Stylophora pistillata. Mar Ecol Prog Ser 311: 93-102

Submitted: February 23, 2007; Accepted: June 24, 2007 Proofs received from author(s): October 31, 2007 